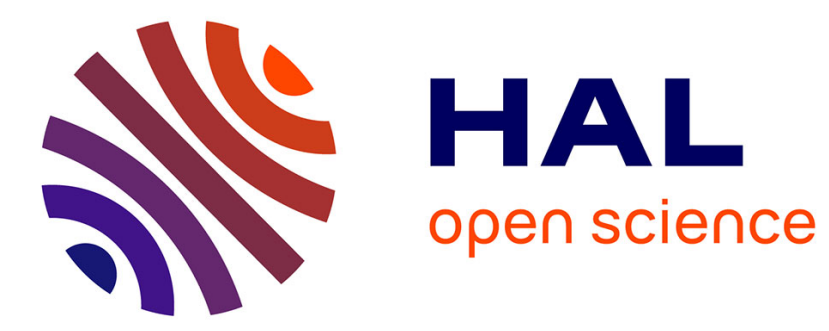

\title{
Meiotic studies in an azoospermic boar carrying a Y;14 translocation
}

Alain Pinton, I. Raymond Letron, Hélène Berland, N. Bonnet, Anne Calgaro, Amélie Garnier, Martine M. Yerle, Alain Ducos

\section{- To cite this version:}

Alain Pinton, I. Raymond Letron, Hélène Berland, N. Bonnet, Anne Calgaro, et al.. Meiotic studies in an azoospermic boar carrying a Y;14 translocation. Cytogenetic and Genome Research, 2008, 120, pp.106-111. 10.1159/000118747 . hal-02662835

\section{HAL Id: hal-02662835 \\ https://hal.inrae.fr/hal-02662835}

Submitted on 31 May 2020

HAL is a multi-disciplinary open access archive for the deposit and dissemination of scientific research documents, whether they are published or not. The documents may come from teaching and research institutions in France or abroad, or from public or private research centers.
L'archive ouverte pluridisciplinaire HAL, est destinée au dépôt et à la diffusion de documents scientifiques de niveau recherche, publiés ou non, émanant des établissements d'enseignement et de recherche français ou étrangers, des laboratoires publics ou privés. 


\title{
Meiotic studies in an azoospermic boar carrying a Y;14 translocation
}

\author{
A. Pinton ${ }^{a} \quad$ I. Raymond Letron ${ }^{b} \quad$ H.M. Berland ${ }^{a} \quad$ N. Bonnet ${ }^{a} \quad$ A. Calgaro ${ }^{a}$ \\ A. Garnier-Bonnet ${ }^{\mathrm{a}}$ M. Yerle $^{\mathrm{a}} \quad$ A. Ducos ${ }^{\mathrm{a}}$ \\ ${ }^{a}$ UMR 444 INRA-ENVT, Génétique Cellulaire, and ${ }^{\mathrm{b}}$ Laboratoire Histo-Pathologie ENVT, Toulouse (France)
}

Accepted in revised form for publication by M. Schmid, 25 October 2007.

\begin{abstract}
A reciprocal translocation between the $\mathrm{q}$ arm of the $\mathrm{Y}$ chromosome and the $\mathrm{q}$ arm of chromosome 14 was identified in a young, phenotypically normal boar presenting azoospermia. Testicular biopsies were analyzed by classical histological and immunolocalization techniques, and by fluorescence in situ hybridization. Meiotic pairing analysis of 85 pachytene spreads showed the presence of an open structure corresponding to a quadrivalent formed by chromosomes 14, X, and the derivative chromosomes 14 and $\mathrm{Y}$ in $84.7 \%$ of the cases. In the remaining cases (15.3\%), a 'tri-
\end{abstract}

valent plus univalent' configuration was observed. Immunolocalization of $\gamma \mathrm{H} 2 \mathrm{AX}$ revealed the presence of this modified histone in the chromatin domains of unsynapsed segments (centromeric region of chromosome 14) and spreading of the $\gamma \mathrm{H} 2 \mathrm{AX}$ signal from the $\mathrm{XY}$ body throughout chromosome 14 in $7.05 \%$ of the cells analyzed. The potential causes of the observed infertility, i.e. activation of meiotic checkpoints and/or silencing of genes necessary for the progression of meiosis, are discussed.

Copyright ๑ 2008 S. Karger AG, Basel
The prevalence of Y-autosome reciprocal translocations in the general human population is very low (1 in 2000) (Nielsen and Rasmussen, 1976; Powell, 1984). This kind of translocation has been observed in both fertile and sterile males (Delobel et al., 1998). The effects on fertility mostly depend on the part of the Y chromosome translocated to the autosome. Translocations of the euchromatic part of the $\mathrm{Y}$ chromosome to non-acrocentric chromosomes, for instance, are frequently associated with azoospermia (Sun et al., 2005).

In addition, in reciprocal Y-autosome translocations, the autosomal parts of both derivative chromosomes are associated with the sex chromosomes that are transcriptionally inactive during prophase I (Monesi, 1965; Solari,

\footnotetext{
Request reprints from Dr. Alain Pinton

UMR 444 INRA-ENVT Génétique Cellulaire

Ecole Nationale Vétérinaire de Toulouse

BP 87614, 23 chemin des Capelles

FR-31076 Toulouse Cedex 3 (France)

telephone: +33 561 193275; fax: +33 561193924

e-mail: a.pinton@envt.fr
}

1974; McKee and Handel, 1993; Turner et al., 2002, 2005; Baarends et al., 2005). Several hypotheses have been proposed to explain the failure of meiosis as a result of this association.

According to different authors, this phenomenon could be due to partial reactivation of the sex body (SB) leading to the expression of some genes located on the $\mathrm{X}$ chromosome (Lifschytz and Lindsley, 1972), or to spreading of the SB inactivation towards the autosomal segments attached to the $\mathrm{SB}$, without reactivation of the latter one (Jaafar et al., 1993).

Until now, very few reports on the analysis of meiosis in individuals carrying Y-autosome translocations have been published. However, the recent development of protein immunolocalization techniques on surface spread spermatocytes now permits accurate analysis of the early stages of meiosis (recombination and pairing of homologous chromosomes). Moreover, recent studies have indicated that meiotic silencing of unsynapsed chromatin (MSUC), including meiotic sex chromosome inactivation (MSCI), could be mediated through recruitment of the kinase ATR by BRCA1 followed by phosphorylation of the histone H2AX (Turner et al., 2005). Therefore immunolocalization 
of $\gamma \mathrm{H} 2 \mathrm{AX}$ on surface spread spermatocytes seems to be a pertinent strategy to identify genetically silenced chromosomal regions during meiosis (Baarends et al., 2005; Turner et al., 2005, 2006).

To our knowledge, the use of such techniques to analyze meiotic synapsis and gene expression in spermatocytes of Y-autosome translocation carriers has been reported only twice (Sun et al., 2005; Sciurano et al., 2007).

The main observations of the authors were 1) gradual heterochromatinization of the autosome arms invading the sex body and 2) enlargement of the $\gamma \mathrm{H} 2 \mathrm{AX}$ signals. Both were more consistent with the second hypothesis of a spreading of inactivation from the sex body to the autosomal parts.

Recently our group identified a Y-autosome translocation $\mathrm{t}(\mathrm{Y} ; 14)$ (q1.1;q1.1) in the pig species (Ducos et al., 2007). We intend to improve our knowledge of the meiotic behavior of Y-autosome translocations by using a fluorescence immunocytogenetic approach to study this case.

\section{Materials and methods}

\section{Animal material}

The 6-month-old boar was recruited from the national systematic control program of young pedigree boars destined for artificial insemination centers (Ducos et al., 2007). Although it was phenotypically normal semen analysis revealed azoospermia.

\section{Cytogenetic and molecular characterization}

Classical cytogenetic analysis (GTG banding) allowed the identification of a reciprocal translocation $\mathrm{t}(\mathrm{Y} ; 14)(\mathrm{q} 1.1 ; \mathrm{q} 1.1)$ (Ducos et al., 2007) (Fig. 1). This result was confirmed by dual color chromosome painting using chromosomes $\mathrm{Y}$ and 14 painting probes as previously described by Pinton et al. (2005).

\section{Histological analysis}

Specimens were routinely processed: tissue was fixed in $10 \%$ buffered formalin, embedded in paraffin wax, cut at $4 \mu \mathrm{m}$ and stained with haematoxylin and eosin.

\section{Fluorescence immunostaining and fluorescence in situ} hybridization

A cell suspension was produced by mechanic dissociation of testicular material and transferred to a centrifuge tube. After deposition of the seminiferous tubule remnants, the supernatant was centrifuged at room temperature at $600 \mathrm{~g}$ for $5 \mathrm{~min}$. The pellet was washed in PBS and finally resuspended in a few drops of fresh PBS. Twenty microliters of cell suspension were mixed with $20 \mu \mathrm{l}$ of $0.05 \%$ Triton X-100 solution (prepared in distilled water) and spread on a microscope slide. After 10 min, the preparation was washed for $10 \mathrm{~min}$ by adding $60 \mu \mathrm{l}$ of $0.04 \%$ Photo-Flo (Kodak) solution and finally fixed with $120 \mu$ l of fixative consisting of $1 \%$ formaldehyde, $0.016 \%$ Triton X-100, $\mathrm{pH} 10$. After a further $10 \mathrm{~min}$, the slides were rinsed in distilled water and air-dried at room temperature.

Immunolocalization of meiotic proteins was performed using primary antibodies at 1:100 dilution in PBT $(1 \times$ PBS, $0.15 \%$ BSA, $0.1 \%$ Tween 20) as follows: rabbit anti-SCP1, rabbit anti-SCP3, mouse anti$\gamma \mathrm{H} 2 \mathrm{AX}$ (Abcam, Cambridge, UK) and human anti-centromere (Antibodies Incorporated, Davis, CA, USA). The slides were incubated overnight at room temperature in a humid chamber. After three 5-min washes in PBS, $0.1 \%$ Tween, the secondary antibodies, i.e. Alexa 594conjugated donkey anti-rabbit IgG, Alexa 488-conjugated goat antimouse IgG (Molecular Probes, Eugene, OR, USA) and AMCA-conjugated donkey anti-human IgG (Jackson ImmunoResearch Laborato- ries, Grove, PA, USA) were applied at 1:100 dilution for $2 \mathrm{~h}$ at $37^{\circ} \mathrm{C}$. After three 5-min washes in PBS, $0.1 \%$ Tween and a brief rinse in distilled water, slides were air-dried and mounted with antifade solution (Vector Laboratories Inc., Burlingame, CA, USA). Capture and analysis of the surface spread spermatocytes were performed using the $\mathrm{Cy}$ tovision FISH imaging system (Applied Imaging, Sunderland, UK).

After synaptonemal complex (SC) analysis, the same cells were subjected to fluorescence in situ hybridization using painting probes generated from flow-sorted or microdissected chromosomes X, Y and 14 (Yerle et al., 1993; Pinton et al., 2003). The probes were labeled with biotin (SSC14), digoxigenin (SSCY) or FITC (SSCX). Biotin was revealed by Alexa 594-conjugated streptavidin (Molecular Probes, Eugene, OR, USA). Digoxigenin was revealed by a mouse anti-digoxigenin antibody (Roche Diagnostic, Meylan, France) and an Alexa 647-conjugated donkey anti-mouse antibody (Molecular Probes, Eugene, OR, USA). The probe labeled with FITC was revealed by a goat anti-FITC antibody (Bethyl, Montgomery, Texas, USA) and an Alexa 488-conjugated donkey anti-goat antibody (Molecular Probes, Eugene, OR, USA). FISH signals of the same cells for which SCs had previously been analyzed were captured and evaluated.

\section{Cot RNA experiment}

A Cot RNA experiment was carried out before immunostaining of the $\gamma \mathrm{H} 2 \mathrm{AX}$ protein (to preserve RNA integrity) according to Turner et al. (2005). The Cot DNA probe was produced from $400 \mathrm{ng}$ of porcine Cot DNA (Applied Genetics Laboratory, Melbourne, FL, USA) labeled with biotin by Nick Translation (Roche Diagnostic, Meylan, France).

\section{Results}

\section{Molecular characterization}

Dual color chromosome painting confirmed the results of classical cytogenetic analysis (Fig. 1) and the presence of a small green signal ( $\mathrm{Y}$ chromosome) on the derivative chromosome 14 proved the reciprocity of the exchange (Fig. 2, arrowhead). Moreover, as expected, the Y painting probe also labeled the pseudoautosomal region on the $\mathrm{X}$ chromosome p arm (Fig. 2, arrow).

This experiment clearly demonstrated that chromosome 14 was almost entirely translocated onto chromosome $Y$ and that the small derivative chromosome was constituted by the centromeric region of chromosome 14 and a small Y chromosomal segment (Yq-ter chromosome segment).

\section{Histology}

Histopathological analysis showed a diffuse atrophy of the seminiferous tubules due to a complete arrest of spermatogenesis associated with a severe diffuse hyperplasia of the Leydig interstitial cells (Fig. 3a). At higher magnification, the epithelium of the tubules showed the presence of spermatogonia and primary spermatocytes in great number but no evidence of further cell maturation. Numerous abnormal cells and cellular debris were observed in the lumen (megalocytosis, multinucleated cells, monstrous cells) (Fig. 3b).

\section{Immunolocalization and FISH analyses}

SC analysis of 85 pachytene nuclei showed the presence of an open structure corresponding to a quadrivalent formed by chromosome 14 , chromosome $\mathrm{X}$, and the derivative chromosomes 14 and $\mathrm{Y}$ in $84.7 \%$ of the cases (Fig. 4). 


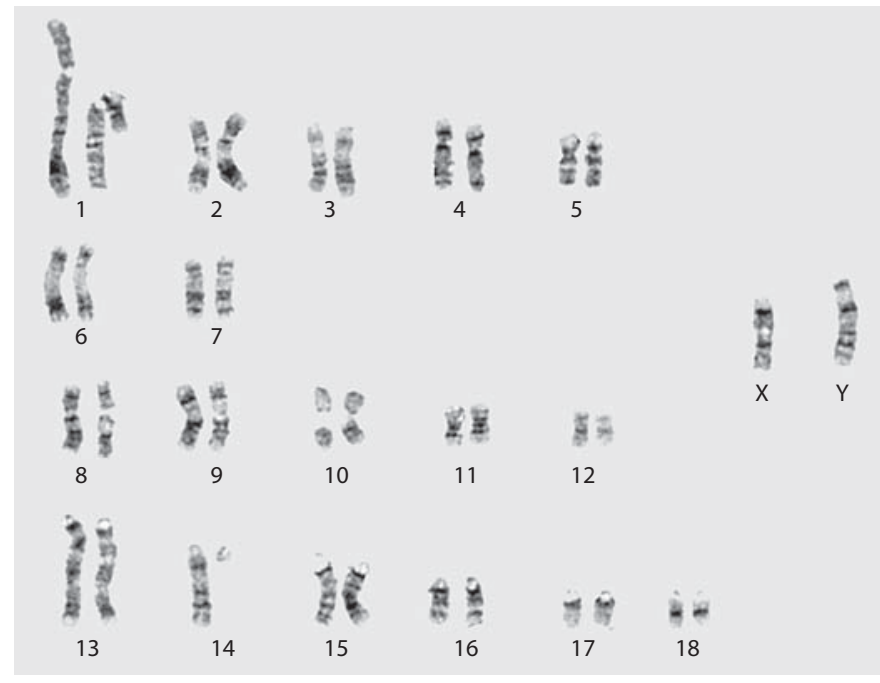

Fig. 1. GTG-banded karyotype of the boar carrying a Y;14 translocation.

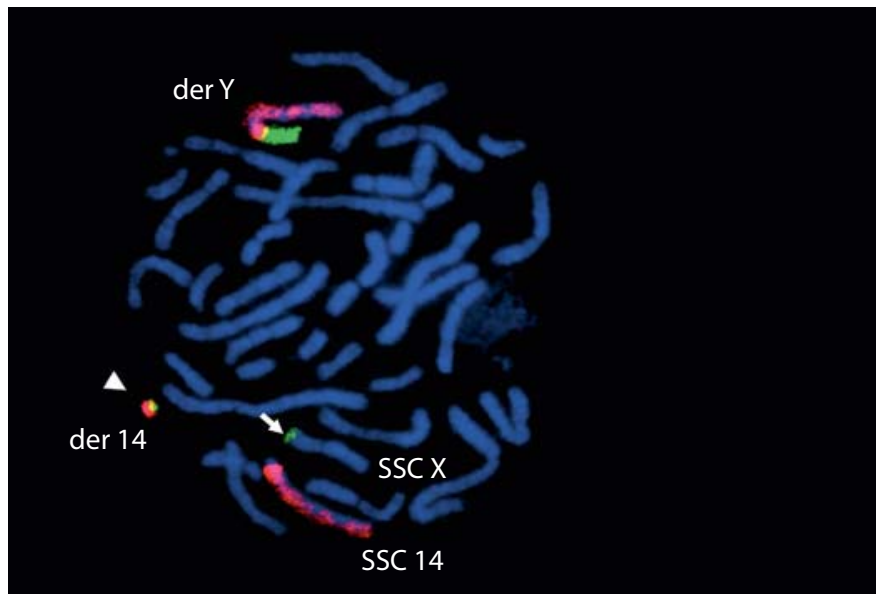

Fig. 2. Metaphase of the translocation-carrying boar after dualcolor chromosome painting (Y probe is revealed in green and chromosome 14 in red). The arrowhead indicates the presence of $\mathrm{Y}$ chromosome material on the derivate chromosome 14 and the arrow the pseudoautosomal region at the extremity of Xp.
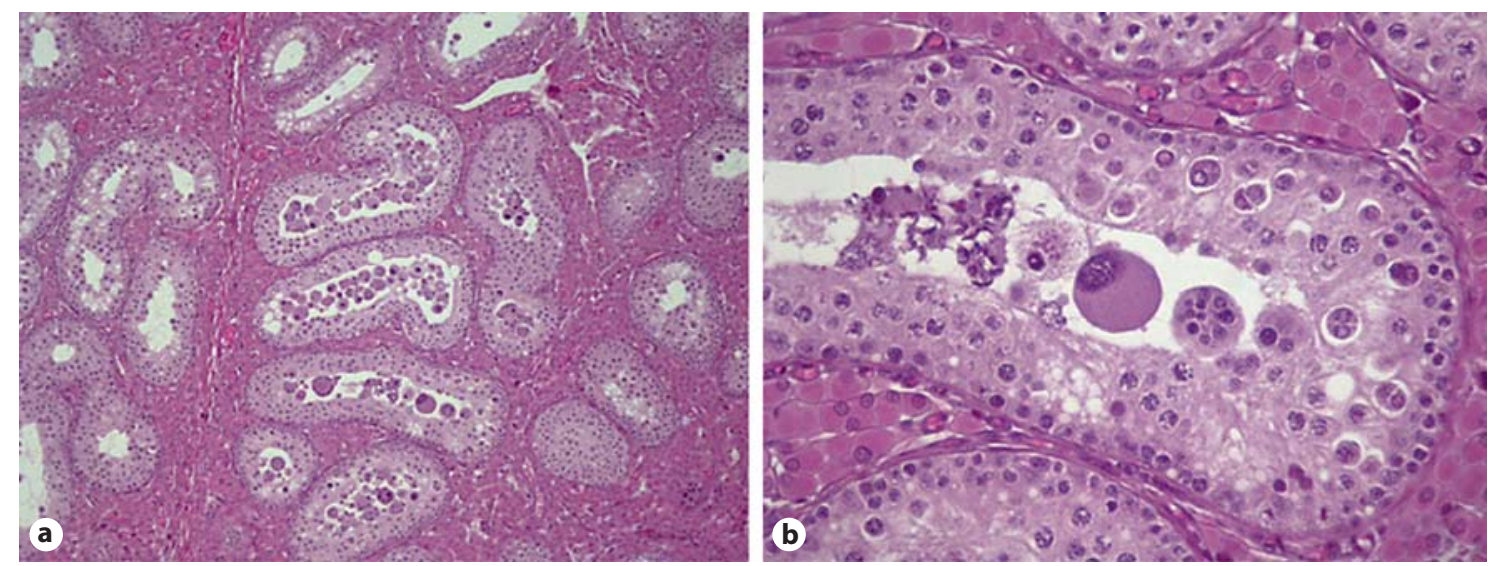

Fig. 3. Histological sections of testicular tissue. (a) Complete arrest of spermatogenesis with hyperplasia of the Leydig interstitial cells $(\times 100)$. (b) Presence of spermatogonia and primary spermatocytes but no evidence of further cell maturation. Abnormal cells and cellular debris are visible in the lumen $(\times 400)$.

A 'trivalent plus univalent' configuration was observed in the remaining cases (15.3\%). The origin of the univalent (derivative chromosome 14) was confirmed by FISH experiments (Fig. 5a2-e2, univalent indicated by the arrowhead).

Immunolocalization of $\gamma \mathrm{H} 2 \mathrm{AX}$ revealed the presence of this modified histone in the chromatin domains of unsynapsed segments (Fig. 5b1, b2, b3). FISH experiments permitted more accurate identification of these regions (Fig. 5c, d, e). In the majority of cells analyzed (92.94\%), the histone accumulated on chromosomes X and Y and on the centromeric region of chromosome 14 in the quadrivalent configurations. Moreover, in the 'trivalent plus univalent' (derivative chromosome 14) configuration, a $\gamma \mathrm{H} 2 \mathrm{AX}$ pos-



Fig. 4. Schematic drawing of the open quadrivalent.

itive signal was always observed on this latter chromosome (Fig. 5b2, arrowhead). Finally in $7.05 \%$ of the cells analyzed, a spreading of the $\gamma \mathrm{H} 2 \mathrm{AX}$ signal from the XY body to the entire chromosome 14 was identified (Fig. 5b3, arrow). 

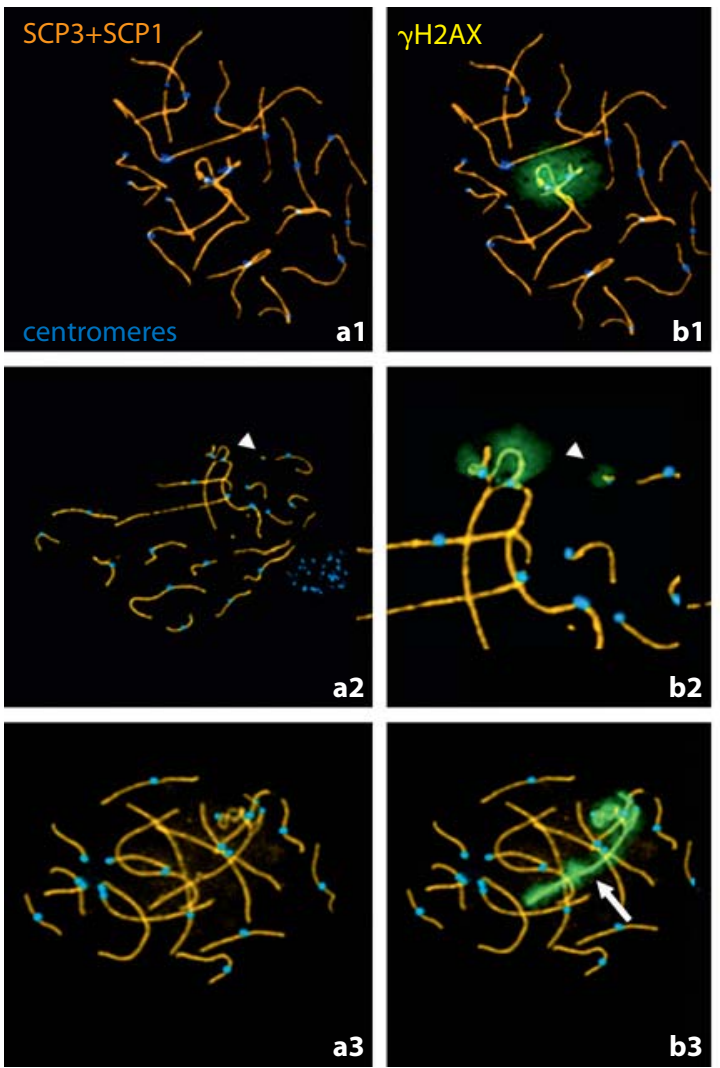
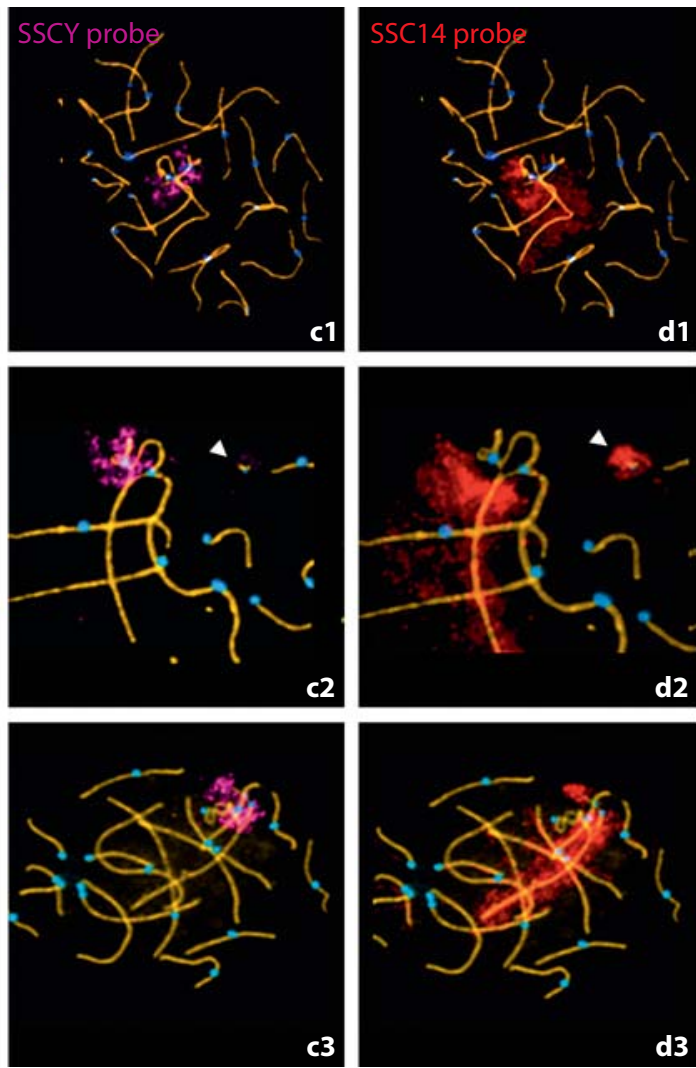


Fig. 5. Spermatocytes after immunolocalization and FISH experiments. (a1-3) Immunolocalization of SCP3, SCP1 and centromeres. (b1-3) Immunolocalization of $\gamma \mathrm{H} 2 \mathrm{AX}$. (c1-3) FISH using chromosome Y probe. (d1-3) FISH using chromosome 14 probe. (e1-3) FISH using chromosome X probe.
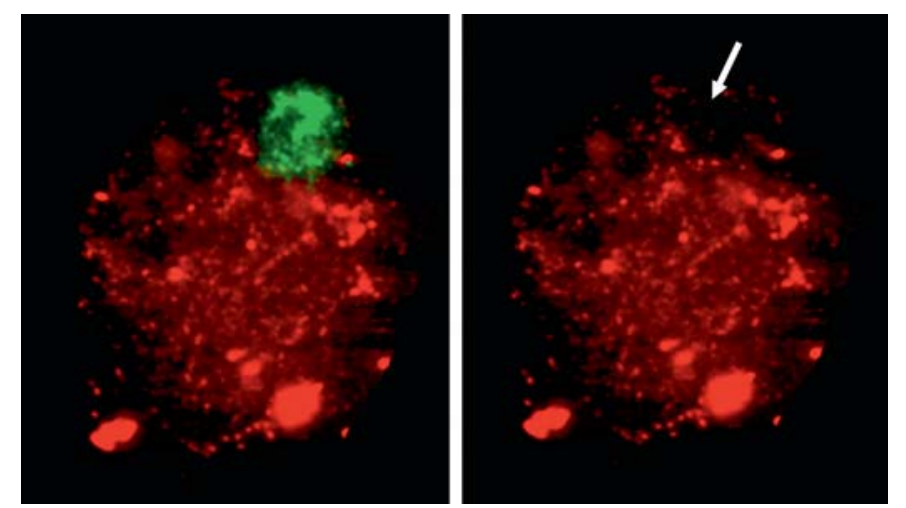

Fig. 6. Cot RNA FISH experiment. Cot DNA positive signals (nascent transcripts) labeled in red and $\gamma \mathrm{H} 2 \mathrm{AX}$ signal in green. Note the absence of Cot signals in the $\gamma \mathrm{H} 2 \mathrm{AX}$-positive area (arrow).

The Cot RNA FISH experiment carried out to analyze the transcription level of the cells revealed a lack of Cot probe signals in the $\gamma \mathrm{H} 2 \mathrm{AX}$ domains suggesting transcriptional repression of these regions (Fig. 6, arrow).

\section{Discussion}

To our knowledge this is the first report of a Y-autosome translocation in pigs. In contrast, several Y-autosome translocations have been identified in humans, frequently associated with spermatogenesis impairment. In our case (azoospermic boar), histopathological analysis revealed that the meiotic process halted during the first division. Previous studies have shown that the arrest of spermatogenesis can be due to synaptic anomalies associated or not with chromosomal abnormalities (see e.g. Oliver-Bonet et al., 2005; Sun et al., 2005, 2007; Martin, 2006; Topping et al., 2006; Sciurano et al., 2007).

The aim of our study was to analyze the early stages of meiosis (using immunolocalization techniques) in order to identify the phenomena potentially responsible for the boar's sterility.

The use of immunolocalization techniques revealed some meiotic abnormalities since SC analysis demonstrated the presence of an open quadrivalent in most cells studied, but also a 'trivalent plus univalent' configuration in some cells ( $15.3 \%$ of the spermatocytes analyzed). The formation of this latter configuration was probably due to meiotic pairing impairments caused by the small size of the deriva- 
tive chromosome 14 . The presence of this univalent can result in a lack of tension of the kinetochores during metaphase I. This phenomenon can be detected by a specific meiotic checkpoint. Indeed, the 'spindle checkpoint' occurs at the metaphase I stage and blocks the metaphase-anaphase transition of cells presenting a defective spindle or misaligned chromosomes (Eaker et al., 2001). In a more general way, the observed meiotic pairing abnormalities (unsynapsed regions in the quadrivalent and 'trivalent plus univalent' configurations) can be detected by another checkpoint, the 'pachytene checkpoint', which occurs during prophase of the first meiotic division (Roeder and Bailis, 2000). This checkpoint may trigger an arrest of the meiotic division. In this case, the presence of unpaired regions (open quadrivalents) and of a univalent in the spermatocytes analyzed could explain the observed arrest of spermatogenesis in this boar.

Our analysis was completed by immunolocalization of the $\gamma \mathrm{H} 2 \mathrm{AX}$ protein (phosphorylated form at serine 139 of the minor histone $\mathrm{H} 2 \mathrm{AX}$ ). This revealed an accumulation of the modified histone in the XY body as well as in the autosomal unsynapsed regions, i.e. the centromeric region of chromosome 14 and the derivative chromosome 14 in the quadrivalent and 'trivalent plus univalent' configurations. These observations are in agreement with the recent results of Sciurano et al. (2007), i.e. presence of $\gamma \mathrm{H} 2 \mathrm{AX}$ in the chromatin domains of the unsynapsed segments of the $\mathrm{X}$ and $\mathrm{Y}$ chromosomes as well as in some autosomal segments. Recent studies in mice have shown that $\gamma \mathrm{H} 2 \mathrm{AX}$-positive domains corresponding to unsynapsed chromatin regions are transcriptionally inactive (Baarends et al., 2005; Turner et al., 2005, 2006). We used Cot RNA FISH to confirm these results in pigs. Our data suggest that the accumulation of $\gamma \mathrm{H} 2 \mathrm{AX}$ correlated with transcriptional silencing of unsynapsed autosomal regions could be responsible for the inactivation of genes located in the centromeric region of chromosome 14 that are crucial for meiotic division, thereby leading to spermatogenesis arrest through apoptosis of the concerned cells.

Recent data available through the pig genome sequencing project ('http://pre.ensembl.org/Sus_scrofa/index.html' - currently release 43 code - Nov 2006) (Hubbard et al., 2007) revealed that some genes involved in the meiotic process are located on chromosome 14 in the region corresponding to the chromosome 14 segment of the derivative chromosome 14. The first one is CKS2 (cyclin-dependent kinase subunit 2) located around $400 \mathrm{~kb}$ from the centromere. Studies carried out in knockout mice for that gene showed that Csk2 is involved in the meiotic process (Spruck et al., 2003). Indeed $C s k 2^{-/-}$mice presented normal early meiotic progression but an arrest of spermatogenesis at metaphase I. The phenotype previously described in these mice is very similar to the observations in the azoospermic boar.

The second gene, located approximately $8 \mathrm{Mb}$ from the centromere of chromosome 14, encodes the Kinesin-like protein KIF13B (Kinesin-like protein GAKIN) that plays a critical role in spindle function and chromosome segrega- tion (Hanada et al., 2000). The inactivation of GAKIN may lead to the inability of chromosomes to segregate at the first meiotic division.

Consequently the meiotic arrest observed in our azoospermic boar could be explained by the inactivation of these two genes (CKS2 and GAKIN).

Gene expression analyses of CKS2 and GAKIN using quantitative RT-PCR will be carried out on RNA extracted from the testicles of the translocation-carrying boar and compared to results obtained from a normal individual. This study will be complemented by RNA FISH experiments using BAC clones containing these two genes.

In a limited number of cases $(7.05 \%)$ the presence of $\gamma \mathrm{H} 2 \mathrm{AX}$ has also been observed on the entire chromosome 14 suggesting a spreading effect of the transcriptional repression from the sex chromosome towards the autosomal translocated chromosome. These observations are coherent with a spreading of the SB inactivation towards the attached autosome segments (Jaafar et al., 1993) rather than gene activation on the X chromosome (Lifschytz and Lindsley, 1972).

Other consequences of meiotic disturbances have been observed in Y-autosome translocation carriers. Sun et al. (2005), for example, reported a decrease of the recombination rate in a man carrying a $(Y ; 1)$ translocation. We tried to analyze the meiotic recombination using antibodies against MLH1 (Baker et al., 1996) but without success. No clear signals of the recombination foci were obtained with these antibodies. This suggests a need to improve the methodology (use of antibodies specific to other recombination proteins such as MLH3 or MSH4). Nevertheless, the occurrence of a similar phenomenon in our case cannot be excluded. Such a decrease in the number of recombination foci, i.e. future chiasmata, could be responsible for inappropriate orientation and segregation of the chromosomes during the first meiotic division. This meiotic disturbance may also be detected by the previously described meiotic checkpoints.

In conclusion our results show the interest and power of immunolocalization techniques for studying the early stages of meiosis. They open up a new way for identifying and understanding the mechanisms of meiotic disturbance. The identification of $\gamma \mathrm{H} 2 \mathrm{AX}$-positive domains in the spermatocytes of individuals exhibiting impaired spermatogenesis could be a first step in the identification of new genomic regions potentially carrying genes involved in the control of meiosis.

\section{Acknowledgements}

We thank Dr. Jordi Benet, Dr. Montserrat Codina Pascual and Dr. Maria Oliver-Bonet for their technical training and assistance. 


\section{References}

Baarends WM, Wassenaar E, van der Laan R, Hoogerbrugge J, Sleddens-Linkels E, et al: Silencing of unpaired chromatin and histone H2A ubiquitination in mammalian meiosis. Mol Cell Biol 25:1041-1053 (2005).

Baker SM, Plug AW, Prolla TA, Bronner CE, Harris $\mathrm{AC}$, et al: Involvement of mouse Mlh1 in DNA mismatch repair and meiotic crossing over. Nat Genet 13:336-342 (1996).

Delobel B, Djlelati R, Gabriel-Robez O, Croquette MF, Rousseaux-Prevost R, et al: Y-autosome translocation and infertility: usefulness of molecular, cytogenetic and meiotic studies. Hum Genet 102:98-102 (1998).

Ducos A, Berland HM, Bonnet N, Calgaro A, Billoux S, et al: Chromosomal control of pig populations in France: 2002-2006 survey. GSE, in press (2007).

Eaker S, Pyle A, Cobb J, Handel MA: Evidence for meiotic spindle checkpoint from analysis of spermatocytes from Robertsonian-chromosome heterozygous mice. J Cell Sci 114:29532965 (2001)

Hanada T, Lin L, Tibaldi EV, Reinherz EL, Chishti AH: GAKIN, a novel kinesin-like protein associates with the human homologue of the Drosophila discs large tumor suppressor in T lymphocytes. J Biol Chem 275:28774-28784 (2000).

Hubbard TJ, Aken BL, Beal K, Ballester B, Caccamo M, et al: Ensembl 2007. Nucleic Acids Res 35: D610-617 (2007).

Jaafar H, Gabriel-Robez O, Rumpler Y: Chromosomal anomalies and disturbance of transcriptional activity at the pachytene stage of meiosis: relationship to male sterility. Cytogenet Cell Genet 64:273-280 (1993).
Lifschytz E, Lindsley DL: The role of X-chromosome inactivation during spermatogenesis (Drosophila-allocycly-chromosome evolutionmale sterility-dosage compensation). Proc Natl Acad Sci USA 69:182-186 (1972).

Martin RH: Meiotic chromosome abnormalities in human spermatogenesis. Reprod Toxicol 22: 142-147 (2006).

McKee BD, Handel MA: Sex chromosomes, recombination, and chromatin conformation. Chromosoma 102:71-80 (1993).

Monesi V: Synthetic activities during spermatogenesis in the mouse RNA and protein. Exp Cell Res 39:197-224 (1965).

Nielsen J, Rasmussen K: Y/autosomal translocations. Clin Genet 9:609-617 (1976).

Oliver-Bonet M, Benet J, Sun F, Navarro J, Abad C, et al: Meiotic studies in two human reciprocal translocations and their association with spermatogenic failure. Hum Reprod 20:683-688 (2005).

Pinton A, Ducos A, Yerle M: Chromosomal rearrangements in cattle and pigs revealed by chromosome microdissection and chromosome painting. Genet Sel Evol 35:685-696 (2003).

Pinton A, Faraut T, Yerle M, Gruand J, Pellestor F, et al: Comparison of male and female meiotic segregation patterns in translocation heterozygotes: a case study in an animal model (Sus scrofa domestica L.). Hum Reprod 20:2476-2482 (2005).

Powell C: Sex chromosomes and sex chromosome abnormalities, in Gersen SL, Keagle MB (eds): The Principles of Clinical Cytogenetics, pp 229-258 (Humana Press, Totowa 1984).

Roeder GS, Bailis JM: The pachytene checkpoint. Trends Genet 16:395-403 (2000).

Sciurano R, Rahn M, Rey-Valzacchi G, Solari AJ: The asynaptic chromatin in spermatocytes of translocation carriers contains the histone variant gamma-H2AX and associates with the XY body. Hum Reprod 22:142-150 (2007).
Solari AJ: The behavior of the XY pair in mammals. Int Rev Cytol 38:273-317 (1974).

Spruck CH, de Miguel MP, Smith AP, Ryan A, Stein $\mathrm{P}$, et al: Requirement of Cks2 for the first metaphase/anaphase transition of mammalian meiosis. Science 300:647-650 (2003).

Sun F, Greene C, Turek PJ, Ko E, Rademaker A, et al: Immunofluorescent synaptonemal complex analysis in azoospermic men. Cytogenet Genome Res 111:366-370 (2005).

Sun F, Turek P, Greene C, Ko E, Rademaker A, et al: Abnormal progression through meiosis in men with nonobstructive azoospermia. Fertil Steril 87:565-571 (2007).

Topping D, Brown P, Judis L, Schwartz S, Seftel A et al: Synaptic defects at meiosis I and non-obstructive azoospermia. Hum Reprod 21:31713177 (2006).

Turner JM, Mahadevaiah SK, Elliott DJ, Garchon HJ, Pehrson JR, et al: Meiotic sex chromosome inactivation in male mice with targeted disruptions of Xist. J Cell Sci 115: 4097-4105 (2002).

Turner JM, Mahadevaiah SK, Fernandez-Capetillo $\mathrm{O}$, Nussenzweig A, Xu X, et al: Silencing of unsynapsed meiotic chromosomes in the mouse. Nat Genet 37:41-47 (2005)

Turner JM, Mahadevaiah SK, Ellis PJ, Mitchell MJ, Burgoyne PS: Pachytene asynapsis drives meiotic sex chromosome inactivation and leads to substantial postmeiotic repression in spermatids. Dev Cell 10:521-529 (2006).

Yerle M, Schmitz A, Milan D, Chaput B, Monteagudo L, et al: Accurate characterization of porcine bivariate flow karyotype by PCR and fluorescence in situ hybridization. Genomics 16:97103 (1993). 